\title{
Network and Cooperation in the Field of Cultural Production: Naguib Mahfouz in Translation
}

https://doi.org/10.33806/ijaes2000.19.2.3

\author{
Linda Alkhawaja \\ Al-Ahliyya Amman University, Jordan
}

\begin{abstract}
Translation is a social practice and cultural product practiced by agents and produced by institutions in different subjects; hence, it can be studied from various sociological perspectives. This study explores translation activity through a network of various human and non-human agents by adopting two sociological theories: Bourdieu's (1993) theory of cultural production and Latour's (1996) Actor-Network Theory (ANT). The study demonstrates how these two theories reveal the effect of agent networks on the field of cultural production and that the more agents are involved in these networks, the stronger their impact will be on the field of cultural production. The impact of networks and the cooperation of agents in the field of cultural production in relation to the translation of the works of Naguib Mahfouz are examined as a case study. The study concludes that high numbers of linkages between agents in networks strongly influence the field of cultural production. This can be seen in the case of Mahfouz's translated works after he was awarded the Nobel Prize in 1988, at which point there was a flood of Arabic to English translations. Finally, the study highlights the value of synthesizing Bourdieu's theory and ANT in the field of translation studies.
\end{abstract}

Keywords: Bourdieu, Latour, Mahfouz, Nobel Prize, translation

\section{Introduction}

In the past two decades, Bourdieu's (1993) theory of cultural production and Latour's (1996) Actor-Network Theory (ANT) have been regarded as some of the most salient theories in the field of sociology in translation studies. This raises serious questions about whether these studies are only a trend in the field. Do they have enduring qualities that will significantly contribute to the field of sociology in translation studies? To answer and clarify these questions, we studied the usefulness of simultaneously applying these two theories to the field of translation studies and examined the different contexts of the field. We also conducted a case study that explored the effects of agents' cooperation within networks of the field of cultural production. In this study, we adopted a case study as our principal research method, because case studies can be used to explore and explain a particular phenomenon. Empirical data from this study will enable us to make objective statements rather than subjective ones (Saunders, Lewis, and Thornhill 2009). Zheng (2017: 1) affirmed that researchers should conduct more empirical research in the field of sociology in translation studies "to make sociology of translation a truly original and productive area of study."

Bourdieu's (1993) theory of cultural production aims to examine a cultural product (any literary or artistic work) in a complex network of agents. These 
agents include individuals or institutions (e.g. writers, critics, publishers, translators) involved in the production, circulation, and consumption of a cultural product. However, this theory deals with agency from the individualistic perspective (Buzelin 2005), which means that it is incapable of analyzing a network of different types of agents. Therefore, in this paper, we have combined Latour's Actor-Network Theory (ANT) with Bourdieu's theory of cultural production to demonstrate how a strong, united network of actors can influence the field of cultural production.

Before Naguib Mahfouz, the only Arab laureate, was awarded the Nobel Prize in 1988, literature translated from Arabic into English had a very small market and was confined to a limited audience (Altoma 2005). After 1988, there was a wave of interest in translating Arabic literary works into English, specifically for the translation of Mahfouz's works ( Tresilian 2008). For example, the number of Arabic literary works translated from Arabic into English between 1966 and 1988 was 66, compared with 288 titles translated between 1988 and 2008 (Alkhawaja 2014).

To understand this impact on the field of translation, this study adopted ANT and Bourdieu's theory in the field of translation studies. This study examined human and non-human agents in the field such as Mahfouz, the publisher American University in Cairo Press (AUCP), translators, and media. It traced and identified the relationship between those actors within their networks and the technical and social aspects of their negotiations. Cavalcante, Esteves, Pires, de Assis, Vasconcelos, Freitas and de Macedo (2017) affirmed that, in ANT, the researcher should investigate the influence of each actor in the network by considering each one as a black box that should be opened and examined to reveal its connections, joints, and networks. Moreover, they asserted that the role of researchers is to trace actors' associations and relations to outline the network of the investigated phenomenon.

This study aimed to understand the roles of the various actors (human and non-human) in a network and trace the complexities and effects of their interactions. Felski (2016) concurred that ANT mainly focuses on describing network actions rather than explaining them. In other words, it aims to describe social events through existing networks rather than explaining these social events, since connections in networks create social entities. Therefore, in this study, we traced connections between humans and non-humans in the field of cultural production for Mahfouz's translated works to reveal the factors that lead to the flows in translations from Arabic into English.

We examined the field of cultural production around the translated works of Mahfouz by exploring heterogeneous networks including organizations (AUCP), agents (e.g. Mahfouz), media, etc. as effects generated in the patterned networks of various actors. Then, we examined the network as a single block rather than separate components and described their effects on the field of cultural production. This research is based on secondary data from a variety of published sources, second-hand interviews with translators, AUCP and reports (e.g Büchler, 
Guthrie, Barbora and Karas 2011). In light of the objectives of this paper, we seek an answer to the following questions:

(1) How do different actors cooperate and interact in a network; and,

(2) how do a strong united network of actors influence the field of cultural production for Mahfouz and cause flows in translations from Arabic into English?

\section{ANT and the field of cultural production: A theoretical framework}

ANT emerged in the 1980s, primarily with the work of the sociologist Bruno Latour (1996). ANT enables the examination of connections and relations between human and non-human agents, or actants, in a network (Callon 1999). According to Latour's theory (1996: 373) an actant is "something that acts or to which activity is granted by others. It implies no special motivation of human individual actors, nor of humans in general." Tracing the associations or relationships between the actants of a network is the main role of ANT. According to Latour (1996: 378, emphasis in original), it is "a network-tracing activity" that aims to understand existing networks between various actants.

Before describing the elements of this theory, it is important to clarify that ANT is not a theory in a theoretical sense; rather, it is an approach or a method of analysis and a way of describing the world (Cressman 2009). A theory explains why things happen; however, ANT is a descriptive method that aims to highlight associations and how they are created and transformed (Cressman 2009).

Associations can be understood in networks of materially heterogeneous elements (Cressman 2009). The network elements can be human or non-human subjects. Therefore, the focus of this research will be on explaining associations and relations rather than explaining a particular phenomenon. For example, we believe that it is a tautology to explain why someone has a powerful position in the government by saying that he has this position because he is rich. In contrast, actor-network theorists want to understand (and show) how he got this powerful position.

The concept translation (the term appears in italics to distinguish it from the normal sense of translation as it is used in the field translation studies) is central to ANT. It refers to the process of finding connections between actants in a network and revealing their involvement in shaping it (Latour 2005). A network (e.g. person, group, media, idea, and/or machine) is an "interactive assembly of actors" (Dolwick 2009: 39) who communicate with one another and "leave a physical trace of some prior activity, which can be followed by a researcher and recorded empirically. Such a trace is made noticeable by conflict/controversy, flows of translation ...". On that basis, one could argue that ANT can explain translation flows in the field of Mahfouz's works in translation by tracing actants' practices in the field and their relationship with each other through networks.

ANT explains that social activities are part of a complex network of actors and relations among them and other entities (Latour 1996). For example, writing a 
book as a social activity involves a network that includes a writer, publisher, material, tools, etc. ANT aims to "follow the actors" (Latour 2005: 12) and "observe as far as possible what they do as much as what they say" (Best and Walters 2013: 1).

In ANT, any social activity or any phenomenon is the result of a heterogeneous network (Latour 2005). Each network functions as a distinct unit that produces actions. After a while, these networks disappear, but the actions of these networks and their authors become visible to the public (Latour 2005). For instance, a famous novel is the result of a network of a successful writer, a wellmanaged publishing house, and a successful social media campaign. All these elements can later disappear, but the novel is still considered famous. Therefore, networks are not always stable, which means that they can collapse over time, and their elements can become separated and visible to the observer (Law 2004). In Mahfouz's case, for instance, different actants contributed to the popularity of Mahfouz's novels in English translation. After Mahfouz's death, he disappeared from the network; however, his novels remain popular.

It is worth noting that the term "agents and actors" are used interchangeably by many scholars in the field of sociology in translation studies ( Buzelin 2005; Wolf 2007) to refer to individuals or social groups such as authors, translators, and editors. The term "actants" is used specifically by Latour (2005) in his ANT to refer to human and non-human agents such as authors, editors, machine, media, and organization.

Bourdieu's (1993) theory of cultural production can be used to examine a cultural product in a complex network of agents who occupy different positions in the field. These positions are determined by different power sources called "capital" (Bourdieu 1992). Capital in the field gives an authorized validation for cultural producers according to the existing standards of the field (Bourdieu 1993).

According to Bourdieu (1992), there are four forms of capital: cultural capital, economic capital, social capital, and symbolic capital. Cultural capital takes three forms: the embodied form (education, knowledge, and experience), the objectified form (books, paintings, and monuments), and the institutionalized form (certificates, diplomas, and awards) (Bourdieu 1992). Economic capital is acquired when agents possess financial resources (money and assets). Social capital can be obtained by accumulating a network of relationships with other agents and institutions in the field or certain organizations. Finally, symbolic capital is only acquired through recognition by others (Bourdieu 1992). For example, a translator can acquire symbolic capital by producing cultural products in the field of translation such as books, translations, and articles, and winning awards or having a good reputation in translation.

For Bourdieu (1993), entering the field means that agents have to have some sort of codification to be accepted and considered as a legitimate member of that field. That is, agents who hold certain capitals in the field become agents of powers who belong to that field. They have the power to initiate practices and influence a cultural product in that field (Bourdieu 1992). For example, AUCP has 
economic and symbolic capitals related to the field of translation because first; it financially supports the publication of Mahfouz's works in translation and, second; is considered one of the largest publishing houses in the Middle East for Arabic literature and Mahfouz's works (AUCP 2019).

Bourdieu's theory of cultural production has been applied widely in the field of translation studies by researchers such as Wolf (2007) and Kung (2009). All these studies examined a cultural product (work of art) by focusing on human actors and their actions including critics, art historians, publishers, gallery directors, and dealers, but they ignored the non-human aspect in the process of producing a cultural product. However, this process cannot work properly without non-human aspects (Doolin and Lowe 2016) such as media, organizations, and texts. Therefore, we designed this research to examine how agents' cooperation in the field of translation enhanced the number of translations from Arabic into English.

A limited number of studies have applied Bourdieu's theory of cultural production in combination with ANT. For example, Buzelin (2005) examined how Bourdieu's theory (1993) can complement Latour's ANT (1996) in the field of translation studies. She studied multiple mediators involved in the process of translating English literature into French. She found that some agents in the field such as translators and publishers have received more attention compared to other agents in the same field. Those literary agents are actively engaged in different networks that influence the process of selling and buying translation rights, international literary exchange, and the level of royalties, and they can strongly influence the circulation of literature through their networks.

According to Buzelin (2005), some important factors might be overlooked when Bourdieu's theory is applied in isolation from ANT as the latter can more efficiently reveal the existence of translation networks. Buzelin concluded that applying the approaches together could provide a better examination of the respective role of individual agents and networks in this process, and offer a more process-oriented approach toward the study of translation products and translation agency. On that basis, this research examined human agents and their contribution to the field through Bourdieu's theory of cultural production and traced the relationship of those human agents with non-human agents through ANT.

Similarly, Kung (2009) applied ANT to examine human actors and networks in relation to the field of literary translation production. He examined an agency network consisting of both human and non-human actors. He investigated the involvement of translators, editors, publishers, and organizations in the network to better understand the role of networks in enhancing the visibility of lesser-known literature, such as Taiwanese novels in the United States. After applying Bourdieu's theory of cultural production and ANT, he concluded that incorporating actors' social power into the network could enhance the status and volume of exported, lesser-known literature. This confirms that applying these two theories together is a valid framework to examine a field with various types of actors. 
This research extends previous research as it fills a gap in existing literature in different ways. First, unlike previous studies, it provides in-depth investigation of connections and associations between actants in a network and how these can influence the field of cultural production. Second, it offers distinctive insights into the real-life context of the field of translation through applying a case study method. Finally, this research supports the view that applying ANT and Bourdieu's theory to the field of translation studies is a useful tool to investigate a particular phenomenon.

Few researchers in the field of translation studies have adopted Latour's ANT to examine the dynamic relationship between different actants in a network and the network's effect on the field of cultural production. Thus, applying both ANT and Bourdieu's framework together to describe how a network of various agents influences the field of cultural production is needed, especially in relation to Arabic literature.

\section{The role of actants in network formation: A case study of Mahfouz's translated works}

ANT seeks to explain how different actors, irrespective of their positions in the network, if removed or added, will affect the function of the whole network (Doolin and Lowe 2016). Human actors act and interact through material objects that introduce their own effects and thus become something more than mere tools. The contributions of non-human actors such as the Nobel Prize, media, and English translations in the field of cultural production remain hidden until one explores their relationship with the field and other actors in the network.

It is worth noting that networks evolve because actants continually join or leave them, which makes the process of examining all actants in a specific network an impossible task. Latour affirmed that one cannot follow actors everywhere, and that is why a researcher is obliged to sort and select actors in the network based on their impact on the network. Human and non-human actors produce effects and play roles in the network and their contribution to the network enables the formation of the network and its efficiency (Ahuja 2000). Their impact on a network can be assessed by examining the benefits provided by those actants and by tracing their relationship with each other (Braga and Suarez 2018).

Research in the field of cultural production begins with actors within networks. Even an actant like a publisher could be regarded as part of another network involving both human and non-human entities, in which the interactions among such actors form the network (Law 1992). According to ANT, any entity such as the publisher should be deconstructed to see how it works among other networks. Law (1992) affirmed that an actor is part of a network and is always a network in itself.

Figure 1 displays the actor network of Mahfouz's translated works. Many actants such as the AUCP, the translators, and the Nobel Foundation, among others, formed a network that helped Mahfouz win the Nobel Prize in Literature, causing a wave of Arabic to English translations of his works. 
Figure 1 shows there are non-human actants in the field of translation. The way human actants (authors, translators, AUCP) interact with non-human actants (fame, the Nobel Prize, money) in the network cannot be understood unless one traces the relationship between actants and how they work together to affect the wider field of cultural production. This demonstrates the need for a research that provides an understanding of the complexity of actants' relationships in a network.

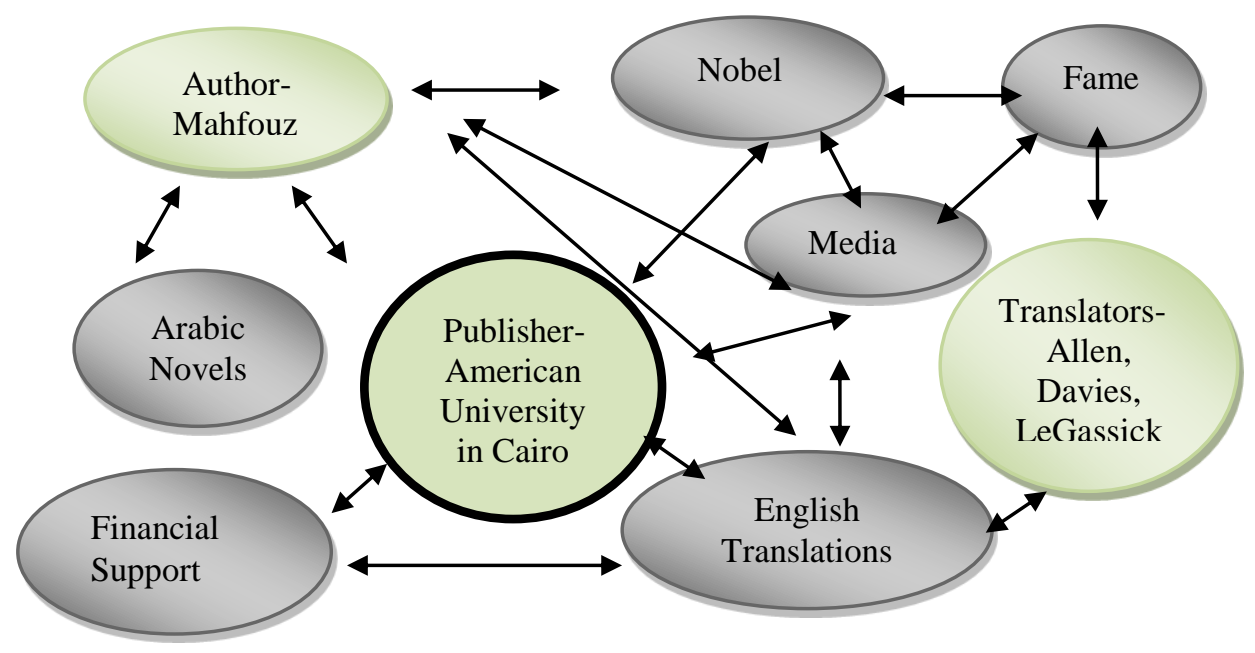

Figure 1. Actor network of Mahfouz's translated works Note. human non-human

To illustrate how the network of relations can influence a field and increase the visibility of its products, we traced the actions of specific agents in the field of cultural production based on their contributions to the field and the amount of capital they acquired in that field. Let us start with one of the main actors in the network: Mahfouz.

Mahfouz is the only Arab author to win the Nobel Prize and, according to Dallal (1998), he is by far the most widely translated Arabic author. One of the main reasons that his works have been translated into English is that they meet English reader s' expectations and suit their tastes (Yousef 2012). As Mahfouz is such a widely translated author, many translators can be considered the main components of his network. The integration of those translators to the network 
brings other translators and publishers into the context of Mahfouz's actor-world where this network can be initiated.

If we unravel the entity of Mahfouz, we can see many other entities including publishers, editors, money, time, and censorship, among other factors. Each of these entities is also a network in itself. For instance, Mahfouz's translations cannot be part of the network without translators to translate his Arabic novels, publishers to initiate translation jobs and pay translators money, and technology to print the translations in book form.

In terms of translators as human actors in the network, many translators, such as Malak Hashim, William Hutchins, Humphrey Davies, and Nancy Roberts, produced products in the field of cultural production for Mahfouz's translated works. Therefore, they became agents with capitals related to that field, and thus, contributed to the dynamics of the field. Those translators are also principal agents in the field of cultural production, as their position in the field is mainly determined by the amount of capitals they acquire in that field (Bourdieu 1992). For example, translator Roger Allen has significantly enriched the field with his translations of Mahfouz's works. He is known for "bringing the work of the only Arab writer to win the Nobel Prize for Literature, Naguib Mahfouz, to an Anglophone audience" (East 2013: 2). Allen was involved in Mahfouz's nomination process for the Nobel Prize in 1988; he supported Mahfouz's nomination and named him as his first choice to the Nobel Prize committee (Altoma 2005: 22).

In addition, translator Johnson-Davies also contributed significantly to the field by translating many of Mahfouz's works into English. Furthermore, translator Trevor LeGassick was the first to translate Mahfouz's works to the English language. LeGassick's translation of Mahfouz's novel, Midaq Alley, was well received among a wide audience, and, as a result, the novel was translated into 15 languages. Thus, translators Allen, Davies, and LeGassick are essential actors in the network of Mahfouz's translated works; because of them, a large number of Mahfouz's books were made accessible to the wider world. They thus supported Mahfouz's position in the network and were partly responsible for the power and influence he wielded on the field of cultural production.

Moreover, relationships between agents in the field of cultural production indirectly established a network of agents from both source and target cultures. We can assert that there are strong relationships between Mahfouz (from the source culture) and his translators (from the target culture). The formation of this network began in 1964, when LeGassick decided to translate one of Mahfouz's novels, Midaq Alley. LeGassick stated in an interview (Alkhawaja 2014) that he went to visit Mahfouz in Cairo and asked him some details about his translation of Midaq Alley. Cooperative relationships between Mahfouz and his translators are evident from the translators' statements. For instance, translator Raymond Stock stated (Dunn 2011: 3) "He [Mahfouz] would introduce me as my friend Raymond Stock, the American poet [...] I had some opportunities to work with him [...] we truly were friends." Similarly, Allen affirmed that, "Over the decades I met Mahfouz many times; my favorite time was when I went to his Tuesday night 
session with his friends" (Braunschweig 2012: 7). Allen (2006: 4) added "1967 was the beginning of a relationship that continued, with intervals, until a final meeting in 2005 on the Farah Boat in Doqqi."

It is interesting to see how agents in the network enacted the process of initiating translations for Mahfouz's works. They indirectly formed a network of agents who communicate with each other and play roles in the network. Therefore, the network of Mahfouz benefited from his connections to other translators in the network.

AUCP is another main agent in the field and a principal actor in the network, as it has contributed significantly to the network's formation through the amount of output it has produced in terms of Mahfouz's translated works (cultural capital). It is one of the largest publishers of English translations of contemporary Arabic literature in the world, and thus has a major influence on the field of cultural production (Büchler et al. 2011). Furthermore, it produces up to 50 new books every year in English and licenses foreign editions of the works of Mahfouz and other Arab writers in 40 languages. To date, AUCP has translated and published 38 works of Mahfouz and has licensed more than 500 foreign-language editions of his works in 40 languages (AUCP 2019).

AUCP entered the network when it signed an agreement with Mahfouz in 1985 authorizing it to become his main English-language publisher and his global agent for all translation rights. As a result, there was a sharp rise in the number of translations for Mahfouz's works (Al-Adwan 2011). This entails an increased demand on translators to be involved in translating Mahfouz's works. There were a limited number of translators who translated Mahfouz's works before 1985 (Jonson-Davies, Le Gassick, Fatma Mahmoud, M. Badawi, Philip Stewart, Olive Kenny, and Ramsis Awad). However, after the 1985 agreement, more translators became involved, including Kristine Henrey, Narriman Warraki, Magdi Wahba, Akef Abadir, Salma Jayyusi, Adnan Haydar, Rasheed El-Enany, and many others (Alkhawaja 2014). Therefore, AUCP increased the number of actors in this network.

In addition, to maintain the construction of this network, AUCP works with the financial resources required to support the network. AUCP financially sponsors the translation and publication of Mahfouz's works. It established the Naguib Mahfouz Fund for Translations of Arabic Literature on 2001 as a way to expand its publishing program of Arabic literature in translation (AUCP 2019b). It has many bookstores and an extensive international publishing program that produces 50 new books and maintains 800 titles for distribution every year (AUCP 2019b). This encouraged translators to translate Mahfouz's works (Kung 2009). AUCP can also make use of its relationships with other publishers in the US. Thus, with its financial support and its own network of relations, AUCP enhanced the formation of the Mahfouz network by inviting influential actors into it. The sales manager at AUCP (Alkhawaja 2014) affirmed that AUCP works in cooperation with other publishers in the US (e.g., Doubleday) because they have advanced technologies that enable them to publish books quickly. 
Media also played an important role in creating the market for Mahfouz's books. His name was mentioned in mass media such as newspapers and television. For example, many articles were written about Mahfouz, his life, and works in prestigious newspapers in the West such as The Independent, The Guardian, The Telegraph, and the New York Times (McFadden 2006). Interestingly, newspapers strongly influence their readers as "they are largely perceived to be neutral" (Abdullahi-Idiagbon and Akeem 2017: 47). Moreover, Mahfouz received increased media attention after being awarded the Nobel Prize. Somekh (2011) affirmed that he was so "inundated with interview requests that Al-Ahram appointed him a personal secretary and someone to reply to all his mails." Mahfouz stated, "I accepted the interviews and encounters that had to be held with the media, but I would have preferred to work in peace."

Moreover, one of the most essential issues that influenced the network of relationships was Mahfouz winning the Nobel Prize for Literature. This is because the Nobel Prize is considered to provide "global fame and authentication of a writer's work as 'world literature"" (Lawall 1993: 21). Moreover, the award of the Nobel Prize influenced the field of translation significantly, as it increased the number of translations from Arabic into English (Tresilian 2008). In this regard, France (2000) affirmed that after the Nobel Prize, many major publishers started to commission translations specifically for Mahfouz's works.

One could argue that at the very early stages of Mahfouz's network, his Arabic novels could not attain enough attention if they were alone in that network. However, the integration of particular actors in the network (e.g. translators and media) brought other actors into Mahfouz's actor-world. Those actants (human and non-human) in the network surrounding Mahfouz worked together either directly or indirectly and formed strong connections that significantly affected the network's success. In other words, the establishment of strong relationships between different agents in the network enhanced the existence of the field of cultural production for Mahfouz's translated works and increased his translations. A deeper examination of the network of Mahfouz novels in translation showed that human actors in conjunction with non-human actors played a role in attracting more people to the network, thus leading to the Nobel Prize award and contributing to the wave of translations from Arabic into English.

\section{Conclusion}

In this case study of Mahfouz, we examined the ways in which networks with human and non-human actants generate social effects. In particular, we traced the actants' activities that led to Mahfouz's Nobel Prize win in 1988, which in turn affected the field of cultural production by causing a wave of Arabic to English translations. We can conclude that human and non-human actants, irrespective of their position in the network, formed a network that enabled Mahfouz to become a powerful figure in the field of literature. If Mahfouz had remained isolated from other actors in the field, rather than becoming part of a network, he likely would have remained powerless. 
Linda Ahed Alkhawaja

Department of English Language and Literature

Al-Ahliyyah Amman University

1.alkhawaja@ammanu.edu.jo

\section{References}

Abdullahi-Idiagbon, Mohammed Sani and Ameen Akeem. (2017). 'Ideological perspectives in editorial: A critical study of Hallmark editorial'. International Journal of Arabic-English-Studies (IJAES), 17 (1): 47-62.

Ahuja, Gautam. (2000). 'Collaboration networks, structural holes, and innovation: A longitudinal study'. Sage publication. 45(3): 425-455.

Aladwan, Dima. (2011). Translation quality assessment: Naguib Mahfouz's Midaq Alley as case study. Unpublished PhD Thesis, University of Leeds, Leeds, UK.

Alkhawaja, Linda. (2014). The role of social agents in the translation into English of the novels of Naguib Mahfouz. Unpublished PhD Thesis, Aston University, Birmingham, UK.

Allen, Roger. (2006). Naguib Mahfouz: From Cairo to the world.http://www.opendemocracy.net/artsliterature/cairo_mahfouz_3864.jsp (Retrieved on 14 February, 2018).

Altoma, Saleh. (2005). Modern Arabic Literature in Translation. London: Westbourne Grove.

AUCP. (2019). 'About the American University in Cairo Press'. http://www.aucpress.com/t-history.aspx (Retrieved on 07, Feb. 2019).

Best, Jacqueline and William Walters. (2013). 'Translating the sociology of translation'. International Political Sociology, 7(3): 345-349.

Bourdieu, Pierre. (1992). Language and Symbolic Power. Translated from French by Raymond and Adamson, M. Cambridge: Polity Press.

Bourdieu, Pierre. (1993). The Field of Cultural Production: Essays on Art and Literature. New York: Columbia University Press.

Braunschweig, Sue. (2012). Fascinated by the Arab World. http://fascinatedbythearabworld.wordpress.com/tag/egyptian-literature/ (Retrieved on 25 December, 2017).

Büchler, Alexandra, Alice Guthrie, Barbora Černá and Michal Karas. (2011). Literary Translation from Arabic, Hebrew and Turkish into English in the United Kingdom and Ireland, 1990- 2010. Literature across Frontiers, Mercator Institute for Media, Languages and Culture, Aberystwyth University, Wales, UK. https://lafpublications.files.wordpress.com/2011/04/literary-translationfrom-arabic-hebrew-and-turkish-into-english-in-the-united-kingdom-andireland-1990-2010.pdf (Retrieved on 14 June, 2018). 
Buzelin, Helen. (2005). 'How Latour's network theory could complement Bourdieusian analyses in translation studies'. The Translator, 11(2): 193218.

Braga, Camila and Suarez, Maribel. (2018). 'Actor-network theory: new perspectives and contributions to consumption studies'. Rio de Janeiro, 16 (2).

Callon, Michel. (1999). 'Actor-network theory - the market test.' In Hassard, J and Law, J. (eds.), Actor-Network Theory and After. Oxford: Blackwell Publishers.

Cavalcante, Ricardo Bezerra, Cristiano José da Silva Esteves , Mariana Calisto de Assis Pires, Daniela Dias Vasconcelos, Mónica de Melo Freitas , Antonio Sávio de Macedo. (2017). 'The Actor-Network theory as a theoretical methodological framework in health and nursing research'. Texto Contexto Enferm, 26(4).

Cressman, Darryl. (2009), 'A brief overview of actor-network theory: Punctualization, heterogeneous engineering and translation'. http://citeseerx.ist.psu.edu/viewdoc/download?doi=10.1.1.869.2972\&rep=re p1\&type $=$ pdf (Retrieved on 15 Feburary , 2019)

Dallal, Jenine. (1998). 'The perils of Occidentalism: How the Arab novelists are driven to write for western readers'. Times Literary Supplement, 8-9.

Dolwick, Jim S. (2009). 'The social and beyond: Introducing actor-network theory'. Journal of Maritime Archaeology, 4(1): 21-49.

Doolin, Bill and Allan Lowe. (2016). 'To reveal is to critique: Actor-network theory and critical information systems research'. In Willcocks Lisely, Chris Sauer and Mary Lacity (eds). Enacting Research Methods in Information Systems, 1. Palgrave Macmillan, Cham

Dunn, Michael. (2011). Interview with Raymond Stock on Naguib Mahfouz. http://www.meforum.org/3400/raymond-stock-naguib-mahfouz (Retrieved on 20th January, 2018).

East, Ben. (2013). Arabist predicts a bright future for translation. The national: Arts and culture. http://www.thenational.ae/arts-culture/books/arabistpredicts-a-bright-future-for-translation. (Retrieved on 1st July, 2018).

Felski, Rita. (2016). 'Comparison and translation: A perspective from actornetwork theory'. Comparative Literature Studies, 53(4): 751-752.

France, Peter. (2000). The Oxford Guide to Literature in English Translation. Oxford: Oxford University Press.

Kung, SZU-WEN. (2009). 'Translation agents and networks, with reference to the translation of contemporary Taiwanese novels'. Translation Research Projects 2, Pym, Antony and Perekrestenko, Ame. (eds.), 123-138.

Latour, Bruno. (1996). 'On actor-network theory: a few clarifications'. Soziale Welt, 4: 369-381.

Latour, Bruno. (2005), Reassembling the Social: An Introduction to ActorNetwork Theory. UK: Oxford University Press.

Law, John. (1992) 'Notes on the theory of the actor-network: Ordering, strategy and heterogeneity', Systems Practice, (5): 379-93. 
Law, John. (2004). After Method: Mess in Social Science Research. London: Routledge.

Lawall, Sarah. (1993). 'Naguib Mahfouz and the Nobel Prize'. In Michael Beard and Adnan Haydar, (ed.) . Naguib Mahfouz: From Regional Fame to Global Recognition, 21-28. New York: Syracuse University Press.

McFadden, Robertd. (2006). Naguib Mahfouz, 94, Nobel Laureate in literature dies.

New York

Times. https://www.nytimes.com/2006/08/31/books/31mahfouz.html. (Retrieved on 07 February, 2019)

Saunders, Mark, Philip Lewis and Adrain Thornhill. (2009). Research Methods for Business Students. (5th ed.). England: Pearson Education Limited.

Somekh, Sasson. (2011). Memories of Mahfouz. Haaretz. https://www.haaretz.com/1.5003051 (Retrieved 02 March, 2019).

Tresilian, David. (2008). A Brief Introduction to Modern Arabic Literature. London: Saqi.

Wolf, Michaela. (2007). 'The location of the "Translation Field". Negotiating borderlines between Pierre Bourdieu and Homi Bhabha'. In Wolf, Michaela and Alexandra Fukari (eds.), Constructing a Sociology of Translation. Amsterdam: Benjamins.

Yousef, Tawfiq. (2012). 'Literary translation: Old and new challenges'. IJAES, 13 (1): 49-64.

Zheng, Jing. (2017). 'An overview of sociology of translation: past, present and future'. International Journal of English Linguistics, 7 (4): 1-5. 